\title{
Salários, Comércio Internacional e Padrões Tecnológicos
}

\author{
Gílson Geraldino Silva Jr* \\ Daisy Assmann Lima**
}

Resumo: Este artigo traz evidência empírica em painel para os efeitos das importações e exportações brasileiras sobre os salários, dada a escolaridade do trabalhador e o perfil tecnológico das transações com o resto do mundo, utilizando informações setoriais da Rais e da Secex para o período 1996 a 2011. Os resultados sugerem que o comércio do Brasil com outras nações afeta negativamente o nível dos salários, independentemente da escolaridade e do perfil tecnológico. Os prêmios salariais indicam que, no geral, as transações com o resto do mundo ampliam a desigualdade salarial entre os mais qualificados e os menos qualificados e pode ser considerada uma fonte endógena de desigualdade salarial.

Palavras-chave: Salários, comércio internacional, padrões tecnológicos.

Classificação JEL: J31; F16; L60.

* Bacharel e Mestre em Economia (UFMG) e Doutor em Economia (UFRGS). E-mail: gilsongsj@gmail.com

** Bacharel (UnB) e Mestre (UCB) em Economia. E-mail: daisyunb@hotmail.com 


\section{Introdução}

Este artigo traz evidência empírica em painel para os efeitos das importações e exportações brasileiras sobre os salários, dada a escolaridade do trabalhador e o perfil tecnológico das transações com o resto do mundo, utilizando informações setoriais da Rais e da Secex para o período 1996 a 2011. Os resultados sugerem que o comércio do Brasil com outras nações afeta negativamente o nível dos salários, independentemente da escolaridade e do perfil tecnológico. Os prêmios salariais indicam que, no geral, as transações com o resto do mundo ampliam a desigualdade salarial entre os mais qualificados e os menos qualificados e pode ser considerada uma fonte endógena de desigualdade salarial.

\section{Estudos sobre o Tema}

As teorias de comércio de Heckscher-Ohlin (HO) e de StolperSamuelson (SS) dizem que há uma redução na desigualdade salarial entre trabalhadores qualificados e não qualificados em países em desenvolvimento dada a abertura comercial. Como é esperado que em países em desenvolvimento haja abundância de mão de obra não qualificada, então eles se especializam em bens intensivos nesse tipo de mão de obra. Uma abertura ao comércio internacional leva a um aumento na exportação desses produtos, assim como na demanda e consequentemente nos salários da mão de obra não qualificada em relação à demanda de mão de obra qualificada e dos respectivos salários. Esses fatos podem acarretar a redução na desigualdade salarial entre mão de obra qualificada e não qualificada em países em desenvolvimento. Entretanto evidências empíricas da maioria dos países em desenvolvimento não têm logrado êxito em comprovar essas duas teorias (Bas, 2008).

Dessa forma, para estabelecer uma ligação entre o comércio internacional do Brasil com o resto mundo após o período de liberalização e a desigualdade salarial em países em desenvolvimento, devemos considerar outros mecanismos como os padrões tecnológicos de comércio internacional. É esperado que esses fatores devam impactar severamente a desigualdade crescente.

Evidências empíricas sugerem que os argumentos de HO e SS não são observados no mundo real. O equilíbrio geral de HO é baseado em hipóteses muito restritivas tais como competição perfeita, mobilidade perfeita de capital, comércio de bens finais e tecnologia fixa. Dessa maneira, não se estabelece uma conexão com a realidade, tornando difícil testar empiricamente esses modelos.

No modelo SS, em que explica a política de mudança relativa dos preços dos fatores, os preços dos produtos são determinados endogenamente e podem alterar-se por motivos que não necessariamente estejam relacionados com o comércio internacional. Por essas razões, uma relação direta entre bens e fatores como sugerido pelo modelo de equilíbrio geral do comércio não tem sido 
identificado empiricamente.

Outra linha da literatura que explica a crescente desigualdade salarial foca nas políticas protecionistas de comércio. Ou seja, setores intensivos em mão de obra não qualificada são mais protegidos. A liberalização do comércio impacta negativamente no salário dessa mão de obra quando comparada com a mão de obra qualificada pelo corte de tarifas em produtos intensivos em mão de obra não qualificada conforme evidenciado por Hanson e Harrison (1999), por Currie e Harrison (1997), e por Attanasio, Goldberg, e Pavcnik (2004).

A orientação tecnológica de um país pode alterar devido à redução da adoção de políticas protecionistas assim como por meio do aumento do comércio internacional conforme estabelecido por Wood (1997). Essas mudanças no comércio induzidas pelas mudanças tecnológicas são em maioria viesadas por mão de obra qualificada, ou seja, esse comércio viesado para a mão de obra qualificada em tecnologia - trade induced skill biased technological change (SBTC) - demanda mais trabalho qualificado do que de trabalho não qualificado. Devido ao SBTC, o salário do trabalho qualificado deve aumentar quando comparado com o trabalho não qualificado. Segundo Acemoglu (2002), os países em desenvolvimento aumentam a tecnologia existente por meio da importação que torna-se disponível a custos baixos devido à liberalização do comércio e ao aumento do fluxo de capitais. Nesse sentido, há uma justificativa plausível para as mudanças na desigualdade salarial.

Outra parte da literatura que desvia-se da teoria convencional de comércio internacional é a consideração do comércio de produtos intermediários ou do outsourcing ${ }^{1}$. Feenstra \& Hanson (1997) argumentam que a expansão rápida do outsourcing ou da integração da produção mundial explicam, em parte, o aumento na demanda por mão de obra qualificada em países desenvolvidos. Esses países procuram a redução do custo da produção e esse fato interfere na demanda por mão de obra não qualificada dos países em desenvolvimento onde esse tipo de mão de obra é mais barata. E isso leva a uma redução na demanda por mão de obra não qualificada nos países desenvolvidos e a um aumento na desigualdade salarial. Por outro lado, países desenvolvidos terceirizam parte da produção em países em desenvolvimento que são realizadas por mão de obra qualificada de países em desenvolvimento. Nesses casos, o aumento da demanda por mão de obra qualificada em países em desenvolvimento aumenta a desigualdade salarial nesses países.

Hummels, Ishii e Yi (2001) sugerem que uma redução modesta nos custos do comércio podem levar a um aumento significativo no volume do comércio, estimulando a especialização vertical ${ }^{2}$. Portanto há um significado para o "outsourcing" em termos de desigualdade salarial principalmente quando nos referimos a países em desenvolvimento.

Os resultados dessa literatura mostraram que a maioria do aumento da desigualdade salarial é devido a mudanças na estrutura de produção. Parte pode ser explicada por outsorcing que envolve mão de obra não qualificada em

1 Outsourcing é a mudança da produção para outros países.

2 Especialização vertical é caracterizada pela integração na mesma cadeia produtiva, ocorrendo, portanto, em diferentes nichos de mercado. 
quantidade no processo produtivo que por essa razão acaba sendo deslocada para países com mão de obra barata como identificado por por Krugman (2008).

Alguns estudos empíricos têm tentado controlar os fatores que não são diretamente relacionados com o fluxo do comércio internacional. Nesses estudos foi utilizada a equação de salário mincerian (Mincer 1997) que é baseada na teoria do capital humano em que fatores como educação e experiência afetam a desigualdade salarial. Entre os trabalhos empíricos que levaram em consideração o fator capital humano estão Attanasio et. alli (2004) para a Colômbia e Kijima (2006) para a Índia.

Aparentemente pode haver alguma ligação entre o fato de países como a China, a Índia, o México e o Brasil terem aumentado seu comércio com países desenvolvidos e concomitantemente a desigualdade salarial nos Estados Unidos e na Europa ter também crescido, entretanto estudos empíricos como de Acemoglu (2002) e Bergman et alli (1994) mostraram que o comércio não é a principal causa das desigualdades salariais, mas sim a mudança tecnológica. Há, ainda, trabalhos que evidenciam não haver essa relação, ou seja, os salários relativos da mão de obra não qualificada caíram também em países em desenvolvimento e esse fato contradiz as previsões da teoria de Heckscher-Ohlin conforme Hanson e Harrison (1999) e Berman, Bound e Machin (1997).

Outra visão da literatura tem mostrado que o comércio pode afetar os incentivos em adotar e desenvolver novas tecnologias. Assim a evidência empírica de que a tecnologia é altamente correlacionada com as mudanças nas diferenças salariais não indica que o comércio internacional não exerça influência nessa relação, mas sim que o comércio está afetando a tecnologia e esta é uma variável que altera a demanda por mão de obra qualificada como identificado por Butler e Dueker (1999) e Chusseau e Hellier (2007).

\section{3 "Efeito China"}

Em menos de três décadas a China obteve um papel não negligenciável no comércio internacional tornando-se uma das maiores economias exportadoras assim como importadoras. Bloom et alli (2009) sustentam que os estudos até então realizados sobre o efeito das importações chinesas sobre as desigualdades salariais têm subestimado o impacto positivo do comércio chinês sobre o progresso tecnológico.

Ainda segundo Bloom et alli (2009) estimaram o impacto do crescimento da importação chinesa usando um painel de aproximadamente 23.000 estabelecimentos europeus em 2007. Os principais resultados da competição da importação chinesa levaram a um aumento da tecnologia e ao realocamento de emprego que exige mão de obra mais intensiva em tecnologia. Esses efeitos estão aumentando à medida que o volume do comércio chinês cresce, contribuindo para o aumento de tecnologia em cerca de $30 \%$ nos últimos anos. Dessa forma, o comércio da China com países de baixos salários possuem efeitos positivos para o progresso tecnológico.

Em termos de conjuntura econômica, Bloom et alli (2009) verificaram que 
muitos políticos na Europa e nos Estados Unidos têm se mostrado resistentes quanto ao comércio crescente com a China.

Entretanto há benefícios que são apontados pelos autores não considerados nas formulações dessas políticas econômicas protecionistas. Por exemplo, a redução do preço dos bens para o consumidor final além de induzir ao aumento do progresso tecnológico por meio da inovação e da adoção de novas tecnologias.

Essencialmente a contribuição do trabalho de Bloom et alli (2009) está em confirmar a importância do comércio de países com baixos salários para a mudança tecnológica utilizando microdados das firmas.

Portanto há evidências no sentido de que tanto o comércio quanto a tecnologia afetam os prêmios salariais. E isso ocorre de maneira diferenciada, mas sem deixar de contribuir conjuntamente. Entretanto não percebemos pela literatura qual a contribuição de cada nível de tecnologia para o diferencial salarial para cada nível de escolaridade. Nesse ponto pretendemos agregar resultados à literatura existente.

Dados os fatos acima relacionados que são importantes em determinar a relação entre comércio e desigualdades salariais, e ainda considerar que a globalização intensificou as relações entre o comércio e o mercado de trabalho tomaremos como variáveis relevantes para a diferença salarial as exportações e as importações e variáveis dummies para o nível de padrão tecnológico que se enquadra cada setor considerado.

\section{As Bases de dados e as Variáveis}

Esta análise emprega dados da RAIS de 1996 a 2011. Os dados obtidos foram de escolaridade, de faixa etária, de gênero conforme a classificação CNAE 95 para o período compreendido de 1996-2005 e CNAE 2.0 para 2006-2011. Outra parte dos dados foi obtida da Secex (Secretaria de Comércio Exterior) vinculada ao MDIC (Ministério do Desenvolvimento, Indústria e Comércio Exterior) na parte relacionada às estatísticas de comércio exterior. Os dados obtidos foram referentes às exportações e importações brasileiras agregadas por padrão tecnológico também para o período 19962011. A classificação adotada pela Secex segue o padrão adotado pela OCDE por intensidade tecnológica, que utiliza a intensidade em P\&D (gastos de P\&D/valor adicionado ou gastos de $\mathrm{P} \& \mathrm{D} /$ produção) para classificar os setores industriais da seguinte forma:

- Alta Intensidade Tecnológica: aeroespacial, farmacêutica, informática, eletrônica e telecomunicações, instrumentos.

- Média-Alta Intensidade Tecnológica: material elétrico, veículos automotores, químico excluído o setor farmacêutico, ferroviário e de equipamentos de transporte, máquinas e equipamentos, editorial e gráfica. 
- Média-Baixa Intensidade Tecnológica: construção naval, borracha e produtos plásticos, coque, produtos refinados de petróleo e de combustíveis nucleares, outros produtos não metálicos; metalurgia básica e produtos metálicos;

- Baixa Intensidade Tecnológica: outros, reciclagem, madeira, papel e celulose, alimentos e bebidas, fumo, têxtil, confecção, couro e calçados.

Por meio da classificação por intensidade tecnológica é possível identificar algumas diferenças estruturais entre o padrão de esforços de inovação e de mudança tecnológica de países desenvolvidos e em desenvolvimento, sendo que a intensidade tecnológica descreve, em geral, a velocidade de deslocamento da fronteira tecnológica internacional. Estas bases de dados permitiram construir variáveis que podem ser dividas em dois tipos basicamente: de níveis de escolaridade e de comércio exterior.

a) Esc_alta: representa o salário médio real das pessoas que possuem graduação ou escolaridade superior.

b) Esc_média: representa o salário médio real das pessoas que possuem escolaridade média (segundo grau ou ensino médio).

c) Esc_baixa: representa o salário médio real das pessoas que possuem escolaridade baixa, ou seja, até a $8^{\text {a }}$ série do ensino fundamental desconsiderando os analfabetos.

d) Ps_am: prêmio salarial entre escolaridade alta e média.

e) Ps_ab: prêmio salarial entre escolaridade alta e baixa.

f) Ps_mb: prêmio salarial entre escolaridade média e baixa.

g) Imp: importações realizadas pelo Brasil em bilhões de reais.

h) Exp: exportações realizadas pelo Brasil em bilhões de reais.

i) Exp_dat: exportações realizadas pelo Brasil em bilhões de reais de produtos industriais de alta tecnologia.

j) Exp_dmat: exportações realizadas pelo Brasil em bilhões de reais de produtos industriais de média-alta tecnologia.

k) Exp_dmbt: exportações realizadas pelo Brasil em bilhões de reais de produtos industriais de média-baixa tecnologia.

1) Imp_dat: importações realizadas pelo Brasil em bilhões de reais de produtos industriais de alta tecnologia.

m) Imp_dmat: importações realizadas pelo Brasil em bilhões de reais de produtos 
industriais de média-alta tecnologia.

n) Imp_dmbt: importações realizadas pelo Brasil em bilhões de reais de produtos industriais de média-baixa tecnologia.

\section{Modelos a Estimar}

Trata-se de dados em painel com dimensão temporal abrangendo um período de 16 anos (1996-2011), e que considerando os 4 padrões tecnológicos definidos pela OCDE e que se constitui em 19 setores, resultou numa dimensão transversal de 304 setores/padrões tecnológicos. As regressões de dados em painel possuem efeitos fixos dos 19 setores. Vale considerar que foram estimados tanto os salários em nível quanto os prêmios salariais. Assim foi identificada a influência do comércio internacional tanto em termos de nível salarial para determinado grau de escolaridade quanto em termos de contribuição para o prêmio salarial. ${ }^{3}$

Com relação às regressões, espera-se que os coeficientes referentes ao comércio internacional (exportações e importações) contribuam negativamente tanto para o nível salarial, independentemente do grau de escolaridade, quanto para os prêmios salariais. Algo razoável, pois as exportações brasileiras são de produtos de baixa tecnologia ao passo que as importações ocorrem em produtos de alta tecnologia. E o padrão das exportações aumenta a remuneração da mão de obra estrangeira, reduzindo o nível salarial da mão de obra brasileira.

Já para as importações de alta tecnologia, há maior demanda por mão de obra qualificada, reduzindo o nível salarial da mão de obra independentemente do grau de escolaridade uma vez que as importações não exigem mão de obra qualificada, mas sim apenas a montagem, caracterizando o fenômeno do outsourcing. Isso procede em decorrência do processo de globalização que intensifica as relações de trabalho.

Entretanto espera-se que haja sinal positivo dos coeficientes de exportação e importação para os diferentes padrões tecnológicos quando regredirmos os prêmios salariais entre mão de obra com escolaridade alta e escolaridade média. De fato, quando trata-se desse tipo de qualificação da mão de obra, temos que há um aumento do diferencial salarial já que tanto a importação quanto a exportação de bens com elevado padrão tecnológico invariavelmente demandarão qualificação da mão de obra.

\footnotetext{
3 Segundo Silva (2011), conforme verificado pelas estatísticas descritivas a maior parte da renda dos trabalhadores está abaixo de 4 salários mínimos, $75 \%$ dos salários estão abaixo de 7 salários mínimos e aproximadamente $20 \%$ dos salários estão entre7 e 23 salários mínimos e 5\% estão acima de 23 salários mínimos. Dessa forma, deveríamos considerar como indexador de preço pelo menos três deflatores diferentes - um para cada grupo de renda. Esse fato poderia trazer ruídos para as regressões dado que cada deflator possui uma metodologia específica. Assim sendo, a unidade salário mínimo (SM) é a segunda melhor opção e não traria prejuízos para a regressão. Ademais o Ministério do Trabalho mostra as estatísticas oficiais em SM por esse motivo.
} 


\section{Estatísticas Descritivas}

A tabela 1 mostra que os trabalhadores de escolaridade baixa nos termos aqui definidos ganharam, em média, no período analisado, cerca de 3,5 salários mínimos. Os de escolaridade média, 6,3, e os de alta, 16,3. Com relação aos prêmios salariais (Tabela 2), o prêmio salarial médio entre escolaridade alta e média no período foi cerca de 3 , entre escolaridade alta e baixa quase 5, e entre média e baixa 1,77. As médias de exportações para este período, por seu turno, concentraram-se em produtos de média alta e baixa tecnologia. E as médias de importações em produtos de alta e média alta intensidade tecnológica (Tabela $3)$.

Tabela 1: Salários médios em salário mínimo (SM) por escolaridade, no Brasil, 1996 - 2011

\begin{tabular}{lrc}
\hline \multicolumn{1}{c}{ Categoria } & Média & Desvio-padrão \\
\hline Escolaridade baixa & 3,511 & 1,564 \\
Escolaridade média & 6,279 & 4,687 \\
Escolaridade alta & 16,294 & 5,627 \\
\hline
\end{tabular}

Fonte: elaboração própria a partir de dados da base Rais-Migra (2012).

Tabela 2: Prêmio salarial dos graus de escolaridade em (SM), no Brasil, $1996-2011$

\begin{tabular}{lcc}
\hline \multicolumn{1}{c}{ Categoria } & Média & Desvio-Padrão \\
\hline Prêmio salarial entre Escolaridade Alta e Média & 3,043 & 0,729 \\
Prêmio salarial entre Escolaridade Alta e Baixa & 4,844 & 1,105 \\
Prêmio salarial entre Escolaridade Média e Baixa & 1,77 & 1,134 \\
\hline
\end{tabular}

Fonte: elaboração própria a partir de dados da base Rais-Migra (2012).

Tabela 3: Exportação e importação por padrão tecnológico em bilhões (R\$) no Brasil, 1996 - 2011

\begin{tabular}{lcc}
\hline \multicolumn{1}{c}{ Categoria } & Média & Desvio-Padrão \\
\hline Exportações & 4,250 & 6,033 \\
Importações & 4,172 & 4,999 \\
$\begin{array}{l}\text { Exportações de Produtos Industriais } \\
\text { de Alta Tecnologia }\end{array}$ & 0,366 & 0,943 \\
$\begin{array}{l}\text { Exportações de Produtos Industriais } \\
\text { de Média-Alta Tecnologia }\end{array}$ & 1,214 & 2,977 \\
$\begin{array}{l}\text { Exportações de Produtos Industriais } \\
\text { de Média-Baixa Tecnologia }\end{array}$ & 1,031 & 3,212 \\
$\begin{array}{l}\text { Exportações de Produtos Industriais } \\
\text { de Baixa Tecnologia }\end{array}$ & 1,638 & 5,392 \\
$\begin{array}{l}\text { Importações de Produtos Industriais } \\
\text { de Alta Tecnologia }\end{array}$ & 1,019 & 2,256 \\
$\begin{array}{l}\text { Importações de Produtos Industriais } \\
\text { de Média-Alta Tecnologia }\end{array}$ & 1,981 & 4,993 \\
\hline
\end{tabular}


Continuação da Tabela 3

\begin{tabular}{lcc}
\hline \multicolumn{1}{c}{ Categoria } & Média & Desvio-Padrão \\
\hline $\begin{array}{l}\text { Importações de Produtos } \\
\text { Industriais de Média-Baixa }\end{array}$ & 0,783 & 2,386 \\
Tecnologia & & 0,997 \\
$\begin{array}{l}\text { Importações de Produtos } \\
\text { Industriais de Baixa } \\
\text { Tecnologia }\end{array}$ & 0,388 & \\
\hline Fonte: elaboração própria a partir de dados da base Secex (2012). &
\end{tabular}

\section{Regressões}

As regressões captam os efeitos das importações e exportações sobre salários e prêmios salariais, dada a escolaridade, cujos resultados estão nas Tabelas 4 a 21, apresentadas no anexo.

De maneira geral, as exportações e importações afetam negativamente os salários, independentemente da escolaridade (Tabelas 4,5, e 6). Com relação aos prêmios salariais, o efeito é fraco e positivo para escolaridade alta e média (Tabela 7), e fraco e negativo entre escolaridade alta e baixa e entre escolaridade média e baixa (Tabelas 8 e 9). Quando consideramos os efeitos de exportações e importações por padrões tecnológicos nos salários, o resultado é invariavelmente negativo para todos os níveis de escolaridade e intensidade tecnológica (Tabelas 10,11 e 12). Idem para as importações (Tabelas 13,14 e 15).

Mas quando consideramos os efeitos de exportações e importações por padrões tecnológicos nos prêmios salariais, o resultado é mais heterogêneo.

O efeito das exportações de alta tecnologia é positivo para todos os prêmios salariais, sendo uma potencial fonte endógena de aumento da desigualdade salarial entre os 3 níveis de qualificação aqui considerados. Porém, as exportações de menor intensidade tecnológica impactam positivamente somente no prêmio salarial entre os trabalhadores de escolaridade alta e média. Nos de escolaridade alta e baixa e escolaridade média e baixa o efeito é negativo, sendo uma potencial fonte endógena de redução da desigualdade salarial entre os 3 níveis de qualificação aqui considerados (Tabelas 16,17 e 18).

Com relação às importações, o efeito é positivo sobre o prêmio salarial entre trabalhadores de escolaridade alta e média independentemente da intensidade tecnológica, sendo também uma potencial fonte endógena de aumento da desigualdade salarial entre estes níveis de qualificação (Tabela 19). Mas é negativo nos prêmios salariais entre trabalhadores de escolaridade alta e baixa e média e baixa, também independentemente da intensidade tecnológica, sendo também uma potencial fonte endógena de redução da desigualdade salarial entre estes outros níveis de qualificação (Tabelas 20 e 21). 


\section{Conclusão}

Estes resultados sugerem que o comércio do Brasil com o resto do mundo afeta negativamente o nível dos salários, independentemente da escolaridade e do perfil tecnológico. Os prêmios salariais indicam que, no geral, as transações com o resto do mundo ampliam a desigualdade salarial entre os mais qualificados e os menos qualificados e pode ser considerada uma fonte endógena de desigualdade salarial. Estas evidências estão de acordo com trabalhos empíricos para outros países, como apontamos na revisão de literatura.

\section{Referências}

Acemoglu, D. (2002) Technical change, inequality and the labour market. Journal of Economic Literature 40: 7-72.

Attanasio O., K. Goldberg and N. Pavcnik (2004), Trade Reforms and Wage Inequality in Colombia, Journal of Development Economics, 74, pp. 331-366.

Bas, Maria. Trade, technology adoption and wage inequalities:theory and evidence. Working Paper n ${ }^{\circ}$ 6/2008. Ecole D'Economie de Paris. 2008.

Berman, E., Bound, J. And Grilichess, Z. (1994) Changes in the demand for skilled labor within U.S. manufacturing: evidence from the annual survey of manufactures. Quarterly Journal of Economics 109: 367-397.

Berman, E., Bound, J. And Machin, S. (1997) Implications of skill-biased technological change: international evidence. Quarterly Journal of Economics 113(4): 1245-1279.

Bloom, Nicholas, Mirko Draca, \& John Van Reenen. 2009. Trade Induced Technical Change? The Impact of Chinese Imports on Diffusion, Innovation, and Productivity. Mimeo, Stanford University.

Butler, Alison; Dueker, Michael. Does foreign innovation affect domestic wage inequality?. Journal of International Economics, v. 47, n. 1, p. 61-89, 1999.

Chusseau, N. And Hellier, J. (2007) Impact de l'ouverture Nord-Sud sur le progr`es technique et les in'egalit'es salariales. Revue Economique 58(2).

Currie, J. \& Harrison, A. (1997). Sharing costs: The impact of trade reform on

Feenstra, R.C. And Hanson, G.H. (1997) Globalization, outsourcing, and wage inequality. American Economic Review, Papers and Proceedings 86(2): 240-245.

Hanson, G. H. \& Harrison, A. (1999). Trade, technology, and wage inequality. Industrial and Labor Relations Review, 52:271-288.

Hummels, David, Jun Ishii, Kei-Mu Yi. 2001. The Nature and Growth of Vertical Specialization in Trade. Journal of International Economics, 54(1): 75-96.

Kijima, Yoko. Why did wage inequality increase? Evidence from urban India 1983- 
99. Journal of Development Economics, v. 81, n. 1, p. 97-117, 2006.

Krugman, Paul R. Trade and wages, reconsidered. Brookings Papers on Economic Activity, v. 2008, n. 1, p. 103-154, 2008.

Mincer, Jacob. (1997). Changes in Wage Inequality, 1970-1990. Research in Labor Economics 16, 1-18.

Silva Jr, G. G. . Market Structure effects on Wages in the Brazilian Industrial Firms.

Estudos Econômicos (USP. Impresso), v. 41, p. 521-536, 2011.

Wood, A. (1997). Openness and wage inequality in developing countries: The Latin American challenge to East Asian conventional wisdom. In Baldwin, R. E., capital and labor in Marroco. Journal of Labor Economics, 15:s44-s71.

\section{Anexo 1 - Resultados Das Regressões}

Tabela 4: efeito de importação e exportação no salário médio em SM por nível de escolaridade baixa , no Brasil, 1996-2011

\begin{tabular}{cccc}
\hline Constante & 4,2121 & $(-0,1127)$ & $*$ \\
Imp & $-0,1023$ & $(-0,0221)$ & $*$ \\
Exp & $-0,0642$ & $(0,0213)$ & $*$ \\
$\mathrm{R}^{2}$ total & & & 0,0372 \\
$\mathrm{R}^{2}$ within & & & 0,1723 \\
$\mathrm{R}^{2}$ between & & & 0,0028 \\
\hline Teste $\mathrm{F}$ & $\mathrm{F}(2,283)=$ & 29,45 & $*$ \\
Observações & & & 304
\end{tabular}

Fonte: elaboração própria a partir de dados da base Rais-Migra (2012).

Convenção: *, **, *** correspondem à significância de $1 \%, 5 \%$ e $10 \%$.

Legenda: Imp são as importações totais em bilhões ( $\mathrm{R} \$$ ) e $\mathbf{E x p}$ são as exportações totais em bilhões $(\mathrm{R} \$)$

Tabela 5: efeito de importação e exportação no salário médio em SM por nível de escolaridade média , no Brasil, 1996-2011

\begin{tabular}{cccc}
\hline Constante & 19,9323 & $(0,3619)$ & $*$ \\
Imp & $-0,5852$ & $(0,0711)$ & $*$ \\
Exp & $-0,2813$ & $(0,0685)$ & $*$ \\
$\mathrm{R}^{2}$ total & & & 0,0331 \\
$\mathrm{R}^{2}$ within & & & 0,3574 \\
$\mathrm{R}^{2}$ between & & & 0,0201 \\
\hline Teste $\mathrm{F}$ & $\mathrm{F}(2,283)=$ & 19,09 & $*$ \\
Observações & & & 304 \\
\hline
\end{tabular}

Fonte: elaboração própria a partir de dados da base Rais-Migra (2012).

Convenção: *, **, *** correspondem à significância de 1\%, 5\% e $10 \%$.

Legenda: Imp são as importações totais em bilhões ( $\mathrm{R} \$)$ e $\mathbf{E x p}$ são as exportações totais em bilhões $(\mathrm{R} \$)$. 
Tabela 6: efeito de importação e exportação no salário médio em SM por nível de escolaridade alta , no Brasil, 1996-2011

\begin{tabular}{cccc}
\hline Constante & 19,9323 & $(0,3619)$ & $*$ \\
Imp & $-0,5852$ & $(0,0711)$ & $*$ \\
Exp & $-0,2813$ & $(0,0685)$ & $*$ \\
$\mathrm{R}^{2}$ total & & & 0,0372 \\
$\mathrm{R}^{2}$ within & & & 0,3574 \\
$\mathrm{R}^{2}$ between & & & 0,0791 \\
\hline Teste $\mathrm{F}$ & $\mathrm{F}(2,283)=$ & 78,71 & $*$ \\
Observações & & & 304 \\
\hline
\end{tabular}

Fonte: elaboração própria a partir de dados da base Rais-Migra (2012).

Convenção: *,**,*** correspondem à significância de 1\%, 5\% e $10 \%$.

Legenda: Imp são as importações totais em bilhões ( $\mathrm{R} \$)$ e $\mathbf{E x p}$ são as exportações totais em bilhões $(\mathrm{R} \$)$

Tabela 7: efeito de importação e exportação no prêmio salarial em SM entre nível de escolaridade alta e média , no Brasil, 1996-2011

\begin{tabular}{cccc}
\hline Constante & 2,7949 & $(0,0633)$ & $*$ \\
Imp & 0,0194 & $(0,0124)$ & $*$ \\
Exp & 0,0394 & $(0,0120)$ & $*$ \\
$\mathrm{R}^{2}$ total & & & 0,0154 \\
$\mathrm{R}^{2}$ within & & & 0,0796 \\
$\mathrm{R}^{2}$ between & & & 0,0092 \\
\hline Teste $\mathrm{F}$ & $\mathrm{F}(2,283)=$ & 12,24 & $*$ \\
Observações & & & 304 \\
\hline
\end{tabular}

Fonte: elaboração própria a partir de dados da base Rais-Migra (2012).

Convenção: *,**, *** correspondem à significância de 1\%, 5\% e $10 \%$.

Legenda: Imp são as importações totais em bilhões ( $\mathrm{R} \$$ ) e $\mathbf{E x p}$ são as exportações totais em bilhões $(\mathrm{R} \$)$.

Tabela 8: efeito de importação e exportação no prêmio salarial em SM entre nível de escolaridade alta e baixa , no Brasil, 1996-2011

\begin{tabular}{cccc}
\hline Constante & 5,0536 & $(0,0765)$ & $*$ \\
Imp & $-0,0423$ & $(0,0150)$ & $*$ \\
Exp & $-0,0076$ & $(0,0145)$ & \\
$\mathrm{R}^{2}$ total & & & 0,0007 \\
$\mathrm{R}^{2}$ within & & & 0,0436 \\
$\mathrm{R}^{2}$ between & & & 0,0580 \\
\hline Teste $\mathrm{F}$ & $\mathrm{F}(2,283)=$ & 6,45 & $*$ \\
Observações & & & 304 \\
\hline
\end{tabular}

Fonte: elaboração própria a partir de dados da base Rais-Migra (2012).

Convenção: *, **, *** correspondem à significância de 1\%, 5\% e $10 \%$.

Legenda: Imp são as importações totais em bilhões ( $\mathrm{R} \$)$ e $\mathbf{E x p}$ são as exportações totais em bilhões $(\mathrm{R} \$)$. 
Tabela 9: efeito de importação e exportação no prêmio salarial em SM entre nível de escolaridade média e baixa , no Brasil, 1996-2011

\begin{tabular}{cccc}
\hline Constante & 2,0689 & $(0,1072)$ & $*$ \\
Imp & $-0,0192$ & $(0,0210)$ & \\
Exp & $-0,0512$ & $(0,0203)$ & $*$ \\
$\mathrm{R}^{2}$ total & & & 0,0071 \\
$\mathrm{R}^{2}$ within & & & 0,0428 \\
$\mathrm{R}^{2}$ between & & & 0,0223 \\
\hline Teste $\mathrm{F}$ & $\mathrm{F}(2,283)=$ & 6,33 & $*$ \\
Observações & & & 304
\end{tabular}

Fonte: elaboração própria a partir de dados da base Rais-Migra (2012).

Convenção: *,**,*** correspondem à significância de 1\%, 5\% e $10 \%$.

Legenda: Imp são as importações totais em bilhões ( $\mathrm{R} \$)$ e $\mathbf{E x p}$ são as exportações totais em bilhões $(\mathrm{R} \$)$.

Tabela 10: efeito das exportações por padrão tecnológico no salário médio em SM para o nível de escolaridade baixa , no Brasil, 1996-2011

\begin{tabular}{cccc}
\hline Constante & 4,4029 & $(0,1027)$ & $*$ \\
Exp_dat & $-1,2291$ & $(0,1402)$ & $*$ \\
Exp_dmat & $-0,2378$ & $(0,0429)$ & $*$ \\
Exp_dmbt & $-0,1474$ & $(0,0382)$ & $*$ \\
$\mathrm{R}^{2}$ total & & & 0,0337 \\
$\mathrm{R}^{2}$ within & & & 0,3024 \\
$\mathrm{R}^{2}$ between & & & 0,5897 \\
\hline Teste $\mathrm{F}$ & $\mathrm{F}(3,282)=$ & 40,75 & $*$ \\
Observaçoes & & & 304
\end{tabular}

Fonte: elaboração própria a partir de dados da base Secex - MDIC (2012).

Convenção: * **, *** correspondem à significância de $1 \%, 5 \%$ e $10 \%$.

Legenda: Exp_dat são as exportações de produtos industriais com alta tecnologia, Exp_dmat são as exportações de produtos industriais com média-alta tecnologia, Exp_dmbt são as exportações de produtos industriais com média-baixa tecnologia, todas as variáveis estão medidas em bilhões de reais. 
Tabela 11: efeito das exportações por padrão tecnológico no salário médio em SM para o nível de escolaridade média , no Brasil, 1996-2011

\begin{tabular}{cccc}
\hline Constante & 8,2183 & $(0,4279)$ & $*$ \\
Exp_dat & $-1,3462$ & $(0,5843)$ & $*$ \\
Exp_dmat & $-0,7446$ & $(0,1789)$ & $*$ \\
Exp_dmbt & $-0,5250$ & $(0,1594)$ & $*$ \\
$\mathrm{R}^{2}$ total & & & 0,0337 \\
$\mathrm{R}^{2}$ within & & & 0,3024 \\
$\mathrm{R}^{2}$ between & & & 0,5897 \\
\hline Teste $\mathrm{F}$ & $\mathrm{F}(3,282)=$ & 11,16 & $*$ \\
Observações & & & 304 \\
\hline
\end{tabular}

Fonte: elaboração própria a partir de dados da base Secex - MDIC (2012).

Convenção: * **, *** correspondem à significância de 1\%, 5\% e 10\%.

Legenda: Exp_dat são as exportações de produtos industriais com alta tecnologia, Exp_dmat são as exportações de produtos industriais com média-alta tecnologia, Exp_dmbt são as exportações de produtos industriais com média-baixa tecnologia, todas as variáveis estão medidas em bilhões de reais.

Tabela 12: efeito das exportações por padrão tecnológico no salário médio em SM para o nível de escolaridade alta , no Brasil, 1996-2011

\begin{tabular}{cccc}
\hline Constante & 19,4947 & $(0,3801)$ & $*$ \\
Exp_dat & $-2,7901$ & $(0,5189)$ & $*$ \\
Exp_dmat & $-1,1338$ & $(0,1589)$ & $*$ \\
Exp_dmbt & $-0,7773$ & $(0,1416)$ & $*$ \\
$\mathrm{R}^{2}$ total & & & 0,0043 \\
$\mathrm{R}^{2}$ within & & & 0,2805 \\
$\mathrm{R}^{2}$ between & & & 0,3311 \\
\hline Teste $\mathrm{F}$ & $\mathrm{F}(3,282)=$ & 36,64 & $*$ \\
Observações & & & 304
\end{tabular}

Fonte: elaboração própria a partir de dados da base Secex - MDIC (2012).

Convenção: *, **, *** correspondem à significância de 1\%, 5\% e $10 \%$.

Legenda: Exp_dat são as exportações de produtos industriais com alta tecnologia, Exp_dmat são as exportações de produtos industriais com média-alta tecnologia, Exp_dmbt são as exportações de produtos industriais com média-baixa tecnologia, todas as variáveis estão medidas em bilhões de reais. 
Tabela 13: efeito das importações por padrão tecnológico no salário médio em SM para o nível de escolaridade baixa , no Brasil, 1996-2011

\begin{tabular}{cccc}
\hline Constante & 4,2157 & $(0,1033)$ & $*$ \\
Imp_dat & $-0,4092$ & $(0,0577)$ & $*$ \\
Imp_dmat & $-0,0899$ & $(0,0229)$ & $*$ \\
Imp_dmbt & $-0,1386$ & $(0,0417)$ & $*$ \\
$\mathrm{R}^{2}$ total & & & 0,0050 \\
$\mathrm{R}^{2}$ within & & & 0,2138 \\
$\mathrm{R}^{2}$ between & & & 0,0803 \\
\hline Teste $\mathrm{F}$ & $\mathrm{F}(3,282)=$ & 25,57 & $*$ \\
Observações & & & 304
\end{tabular}

Fonte: elaboração própria a partir de dados da base Secex - MDIC (2012).

Convenção: * **, *** correspondem à significância de 1\%, $5 \%$ e $10 \%$.

Legenda: Imp_dat são as importações de produtos industriais com alta tecnologia, Imp_dmat são as importações de produtos industriais com média-alta tecnologia, Imp_dmbt são as importações de produtos industriais com média-baixa tecnologia, todas as variáveis estão medidas em bilhões de reais.

\section{Tabela 14: efeito das importações por padrão tecnológico no salário médio} em SM para onível de escolaridade média , no Brasil, 1996-2011

\begin{tabular}{cccc}
\hline Constante & 7,9277 & $(0,4092)$ & $*$ \\
Imp_dat & $-0,6782$ & $(0,2284)$ & $*$ \\
Imp_dmat & $-0,2828$ & $(0,0907)$ & $*$ \\
Imp_dmbt & $-0,5063$ & $(0,1653)$ & $*$ \\
$\mathrm{R}^{2}$ total & & & 0,0160 \\
$\mathrm{R}^{2}$ within & & & 0,0901 \\
$\mathrm{R}^{2}$ between & & & 0,0827 \\
\hline Teste $\mathrm{F}$ & $\mathrm{F}(3,282)=$ & 9,30 & $*$ \\
Observacõos & & & 304 \\
\hline
\end{tabular}

Fonte: elaboração própria a partir de dados da base Secex - MDIC (2012).

Convenção: *, **, *** correspondem à significância de 1\%, 5\% e 10\%.

Legenda: Imp_dat são as importações de produtos industriais com alta tecnologia, Imp_dmat são as importações de produtos industriais com média-alta tecnologia, Imp_dmbt são as importações de produtos industriais com média-baixa tecnologia, todas as variáveis estão medidas em bilhões de reais. 
Tabela 15: efeito das importações por padrão tecnológico no salário médio em SM para o nível de escolaridade alta , no Brasil, 1996-2011

\begin{tabular}{cccc}
\hline Constante & 19,7539 & $(0,3336)$ & $*$ \\
Imp_dat & $-1,7561$ & $(0,1862)$ & $*$ \\
Imp_dmat & $-0,5195$ & $(0,0739)$ & $*$ \\
Imp_dmbt & $-0,8174$ & $(0,1347)$ & $*$ \\
$\mathrm{R}^{2}$ total & & & 0,0014 \\
$\mathrm{R}^{2}$ within & & & 0,3830 \\
$\mathrm{R}^{2}$ between & & & 0,3130 \\
\hline Teste $\mathrm{F}$ & $\mathrm{F}(3,282)=$ & 58,35 & $*$ \\
Observações & & & 304 \\
\hline
\end{tabular}

Fonte: elaboração própria a partir de dados da base Secex - MDIC (2012).

Convenção: *, **, *** correspondem à significância de $1 \%, 5 \%$ e $10 \%$.

Legenda: Imp_dat são as importações de produtos industriais com alta tecnologia, Imp_dmat são as importações de produtos industriais com média-alta tecnologia, Imp_dmbt são as importações de produtos industriais com média-baixa tecnologia, todas as variáveis estão medidas em bilhões de reais.

Tabela 16: efeito das exportações por padrão tecnológico no prêmio salarial em SM entre nível de escolaridade alta e média , no Brasil, 1996-2011

\begin{tabular}{cccc}
\hline Constante & 2,8155 & $(0,0630)$ & $*$ \\
Exp_dat & 0,1402 & $(0,0860)$ & \\
Exp_dmat & 0,1031 & $(0,0263)$ & $*$ \\
Exp_dmbt & 0,0501 & $(0,0234)$ & $*$ \\
$\mathrm{R}^{2}$ total & & & 0,0002 \\
$\mathrm{R}^{2}$ within & & & 0,0739 \\
$\mathrm{R}^{2}$ between & & & 0,0864 \\
\hline Teste $\mathrm{F}$ & $\mathrm{F}(3,282)=$ & 7,51 & $*$ \\
Observações & & & 304
\end{tabular}

Fonte: elaboração própria a partir de dados da base Secex - MDIC (2012).

Convenção: *, **, *** correspondem à significância de 1\%, 5\% e $10 \%$.

Legenda: Exp_dat são as exportações de produtos industriais com alta tecnologia, Exp_dmat são as exportações de produtos industriais com média-alta tecnologia, Exp_dmbt são as exportações de produtos industriais com média-baixa tecnologia, todas as variáveis estão medidas em bilhões de reais. 
Tabela 17: efeito das exportações por padrão tecnológico no prêmio salarial em SM entre nível de escolaridade alta e baixa , no Brasil, 1996-2011

\begin{tabular}{cccc}
\hline Constante & 4,8152 & $(0,0761)$ & $*$ \\
Exp_dat & 0,3063 & $(0,1039)$ & \\
Exp_dmat & $-0,0494$ & $(0,0318)$ & \\
Exp_dmbt & $-0,0222$ & $(0,0234)$ & $*$ \\
$\mathrm{R}^{2}$ total & & & 0,0000 \\
$\mathrm{R}^{2}$ within & & & 0,0399 \\
$\mathrm{R}^{2}$ between & & & 0,0091 \\
\hline Teste $\mathrm{F}$ & $\mathrm{F}(3,282)=$ & 3,91 & $*$ \\
Observações & & & 304 \\
\hline
\end{tabular}

Fonte: elaboração própria a partir de dados da base Secex - MDIC (2012).

Convenção: *, **, *** correspondem à significância de $1 \%, 5 \%$ e $10 \%$.

Legenda: Exp_dat são as exportações de produtos industriais com alta tecnologia, Exp_dmat são as exportações de produtos industriais com média-alta tecnologia, Exp_dmbt são as exportações de produtos industriais com média-baixa tecnologia, todas as variáveis estão medidas em bilhões de reais.

\section{Tabela 18: efeito das exportações por padrão tecnológico no prêmio salarial em SM entre nível de escolaridade média e baixa , no Brasil, 1996-2011

\begin{tabular}{cccc}
\hline Constante & 1,9292 & $(0,1075)$ & $*$ \\
Exp_dat & 0,0384 & $(0,1468)$ & \\
Exp_dmat & $-0,0875$ & $(0,0449)$ & $* *$ \\
Exp_dmbt & $-0,0643$ & $(0,0400)$ & $* * *$ \\
R total & & & 0,0000 \\
$\mathrm{R}^{2}$ within & & & 0,0399 \\
$\mathrm{R}^{2}$ between & & & 0,0091 \\
\hline Teste $\mathrm{F}$ & $\mathrm{F}(3,282)=$ & 2,15 & $* * *$
\end{tabular}

Fonte: elaboração própria a partir de dados da base Secex - MDIC (2012).

Convenção: *, **, *** correspondem à significância de 1\%, 5\% e $10 \%$.

Legenda: Exp_dat são as exportações de produtos industriais com alta tecnologia, Exp_dmat são as exportações de produtos industriais com média-alta tecnologia, Exp_dmbt são as exportações de produtos industriais com média-baixa tecnologia, todas as variáveis estão medidas em bilhões de reais. 
Tabela 19: efeito das importações por padrão tecnológico no prêmio salarial em SM entre nível de escolaridade alta e média , no Brasil, 1996-2011

\begin{tabular}{cccc}
\hline Constante & 2,8851 & $(0,0606)$ & $*$ \\
Imp_dat & 0,0458 & $(0,0338)$ & \\
Imp_dmat & 0,0375 & $(0,1345)$ & $*$ \\
Imp_dmbt & 0,0478 & $(0,0245)$ & $*$ \\
$\mathrm{R}^{2}$ total & & & 0,0123 \\
$\mathrm{R}^{2}$ within & & & 0,0455 \\
$\mathrm{R}^{2}$ between & & & 0,0019 \\
\hline Teste $\mathrm{F}$ & $\mathrm{F}(3,282)=$ & 4,48 & $*$ \\
Observações & & & 304 \\
\hline
\end{tabular}

Fonte: elaboração própria a partir de dados da base Secex - MDIC (2012).

Convenção: *, **, *** correspondem à significância de 1\%, $5 \%$ e $10 \%$.

Legenda: Imp_dat são as importações de produtos industriais com alta tecnologia, Imp_dmat são as importações de produtos industriais com média-alta tecnologia, Imp_dmbt são as importações de produtos industriais com média-baixa tecnologia, todas as variáveis estão medidas em bilhões de reais.

Tabela 20: efeito das importações por padrão tecnológico no prêmio salarial em SM entre nível de escolaridade alta e baixa , no Brasil, 1996-2011

\begin{tabular}{cccc}
\hline Constante & 4,9931 & $(0,0724)$ & $*$ \\
Imp_dat & $-0,0317$ & $(0,0404)$ & \\
Imp_dmat & $-0,0392$ & $(0,0160)$ & $*$ \\
Imp_dmbt & $-0,0491$ & $(0,0292)$ & $*$ \\
$\mathrm{R}^{2}$ total & & & 0,0011 \\
$\mathrm{R}^{2}$ within & & & 0,0324 \\
$\mathrm{R}^{2}$ between & & & 0,0458 \\
\hline Teste $\mathrm{F}$ & $\mathrm{F}(3,282)=$ & 4,48 & $*$
\end{tabular}

Observações

304

Fonte: elaboração própria a partir de dados da base Secex - MDIC (2012).

Convenção: *, **, *** correspondem à significância de 1\%, 5\% e 10\%.

Legenda: Imp_dat são as importações de produtos industriais com alta tecnologia, Imp_dmat são as importações de produtos industriais com média-alta tecnologia, Imp_dmbt são as importações de produtos industriais com média-baixa tecnologia, todas as variáveis estão medidas em bilhões de reais. 
Tabela 21: efeito das importações por padrão tecnológico no prêmio salarial em SM entre nível de escolaridade média e baixa, no Brasil, 1996-2011

\begin{tabular}{cccc}
\hline Constante & 1,9352 & $(0,1019)$ & $*$ \\
Imp_dat & $-0,0329$ & $(0,0569)$ & \\
Imp_dmat & $-0,0383$ & $(0,0226)$ & $*$ \\
Imp_dmbt & $-0,0702$ & $(0,0411)$ & $*$ \\
$\mathrm{R}^{2}$ total & & & 0,0035 \\
$\mathrm{R}^{2}$ within & & & 0,0212 \\
$\mathrm{R}^{2}$ between & & & 0,0214 \\
\hline Teste $\mathrm{F}$ & $\mathrm{F}(3,282)=$ & 2,04 & $* * *$ \\
Observações & & & 304 \\
\hline
\end{tabular}

Fonte: elaboração própria a partir de dados da base Secex - MDIC (2012).

Convenção: *, **, *** correspondem à significância de $1 \%, 5 \%$ e $10 \%$.

Legenda: Imp_dat são as importações de produtos industriais com alta tecnologia, Imp_dmat são as importações de produtos industriais com média-alta tecnologia, Imp_dmbt são as importações de produtos industriais com média-baixa tecnologia, todas as variáveis estão medidas em bilhões de reais. 
